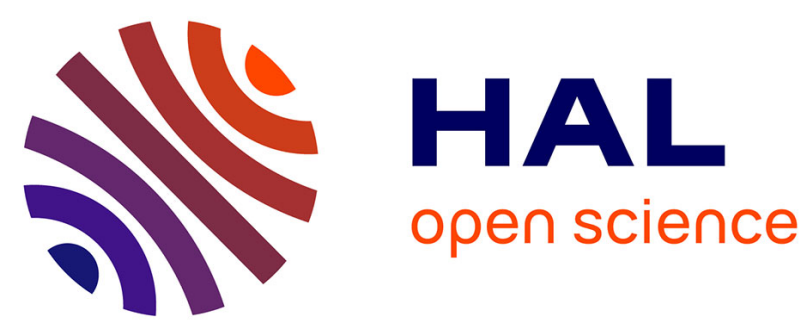

\title{
Intercalation-exfoliation processes during ionic exchange reactions from sodium lepidocrocite-type titanate toward a proton-based trititanate structure
}

Seongkoo Kang, Serge Durand-Vidal, Jean-Claude Badot, Christophe Legein, Monique Body, Olaf J Borkiewicz, Olivier Dubrunfaut, Damien Dambournet

\section{To cite this version:}

Seongkoo Kang, Serge Durand-Vidal, Jean-Claude Badot, Christophe Legein, Monique Body, et al.. Intercalation-exfoliation processes during ionic exchange reactions from sodium lepidocrocite-type titanate toward a proton-based trititanate structure. Physical Chemistry Chemical Physics, 2021, 10.1039/d1cp00352f . hal-03212303

\section{HAL Id: hal-03212303 \\ https://hal.sorbonne-universite.fr/hal-03212303}

Submitted on 29 Apr 2021

HAL is a multi-disciplinary open access archive for the deposit and dissemination of scientific research documents, whether they are published or not. The documents may come from teaching and research institutions in France or abroad, or from public or private research centers.
L'archive ouverte pluridisciplinaire HAL, est destinée au dépôt et à la diffusion de documents scientifiques de niveau recherche, publiés ou non, émanant des établissements d'enseignement et de recherche français ou étrangers, des laboratoires publics ou privés. 


\section{Electronic Supporting Information}

\section{Intercalation-exfoliation processes during ionic exchange reaction from the sodium lepidocrocite- type titanate toward the proton-based trititanate structure}

Seongkoo Kang, ${ }^{a, b}$ Serge Durand-Vidal, ${ }^{a, b *}$ Jean-Claude Badot, ${ }^{b, c}$ Christophe Legein, ${ }^{d}$ Monique Body, ${ }^{\mathrm{d}}$ Olaf J. Borkiewicz, ${ }^{\mathrm{e}}$ Olivier Dubrunfaut, ${ }^{\mathrm{f}}$ and Damien Dambournet ${ }^{\mathrm{a}, \mathrm{b} *}$

${ }^{a}$ Sorbonne Université, CNRS, Physicochimie des Electrolytes et Nanosystèmes Interfaciaux, PHENIX, F-75005, Paris, France

${ }^{b}$ Réseau sur le Stockage Electrochimique de l'Energie (RS2E), FR CNRS 3459, 80039 Amiens, France

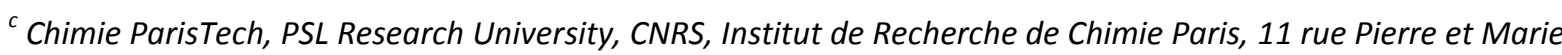
Curie, 75005 Paris, France

${ }^{d}$ Institut des Molécules et Matériaux du Mans (IMMM) - UMR 6283 CNRS, Le Mans Université, Avenue Olivier Messiaen, 72805 Le Mans Cedex 9, France

${ }^{e}$ X-ray Science Division, Advanced Photon Source, Argonne National Laboratory, Argonne, Illinois 60439, United States

${ }^{f}$ GeePs Group of Electrical Enginering - Paris, UMR CNRS 8507, CentraleSupélec, Sorbonne Université, Univ Paris-Sud, Université Paris-Saclay, 11 rue Joliot-Curie, 91192 Gif-sur Yvette, France 
a

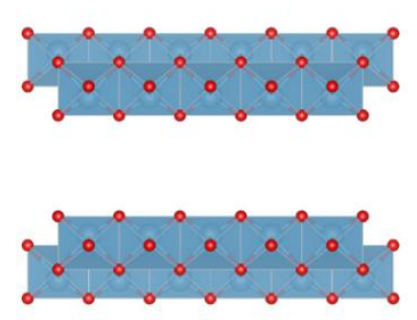

b

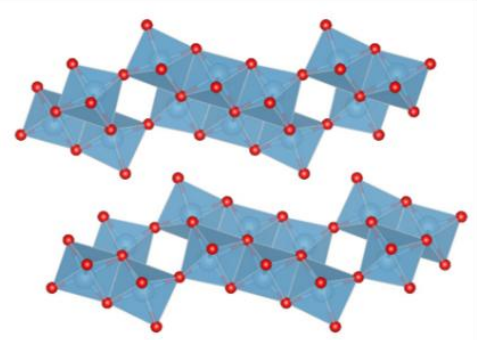

Fig. S1. Structural representation of a) lepidocrocite and b) trititanate structure.

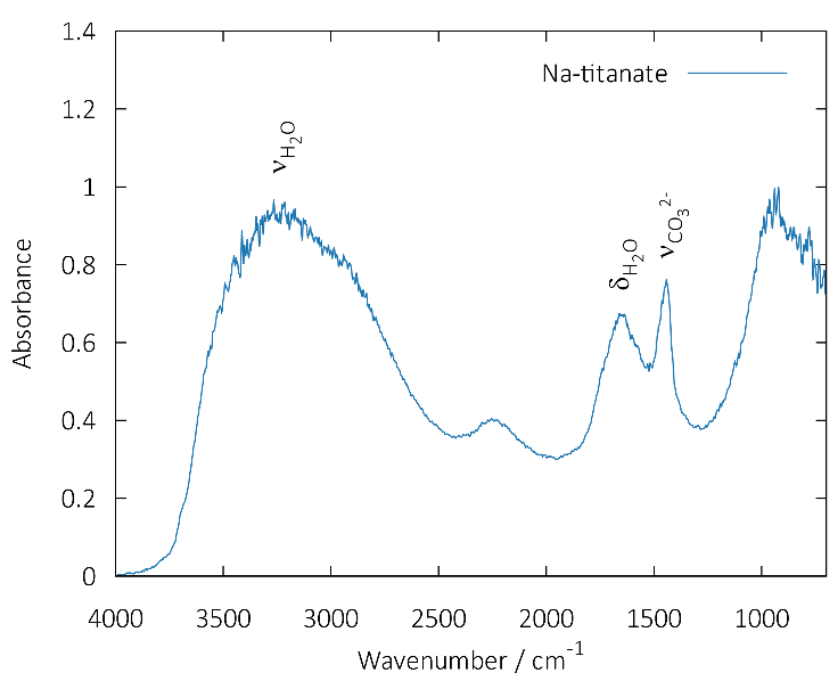

Fig. S2. ATR FT-IR spectrum of Na-titanate. 


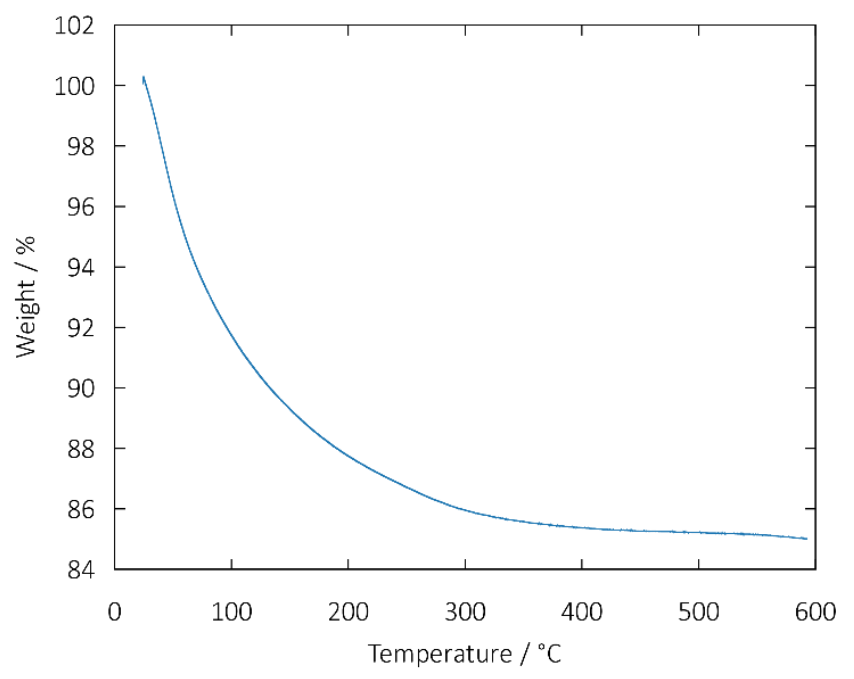

Fig. S3. Thermogravimetric analysis curve of Na-titanate.

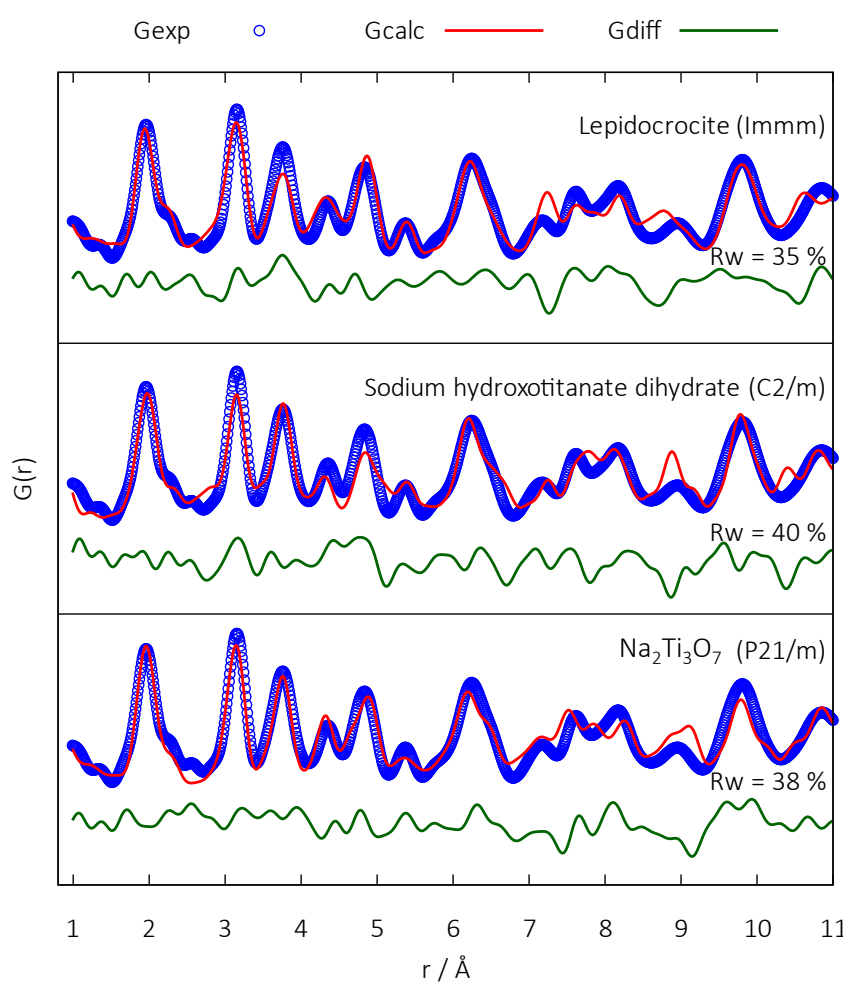

Fig. S4. PDF refinements of Na-titanate using different structural models. 

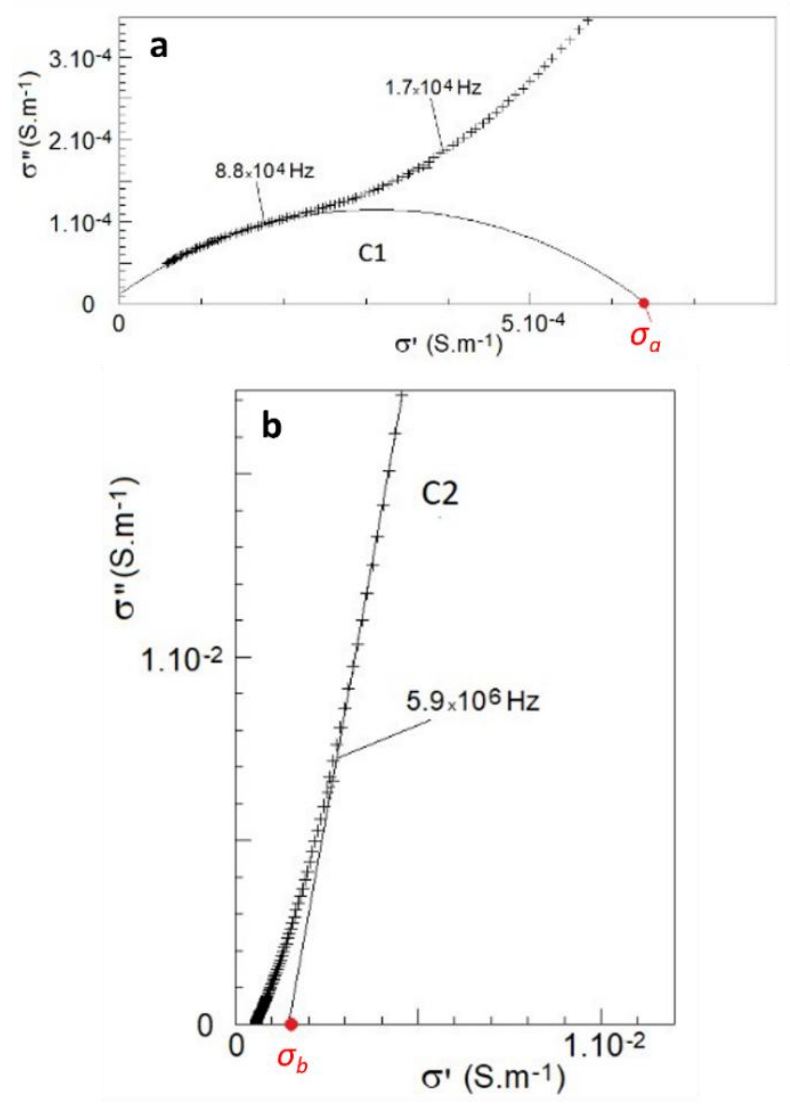

Fig. S5. Nyquist plots of conductivity at RT.

a) Low-frequency contribution (double layer capacitance) C1 fitted with a circular arc. b) Grain bulk contribution fitted with a straight line obtained after the subtraction of $\mathrm{C} 1$. $\sigma_{a}=6.4 \cdot 10^{-4} \mathrm{~S} / \mathrm{m}$ and $\sigma_{b}=1.5 \cdot 10^{-3} \mathrm{~S} / \mathrm{m}$ are sample and grain conductivities, respectively.

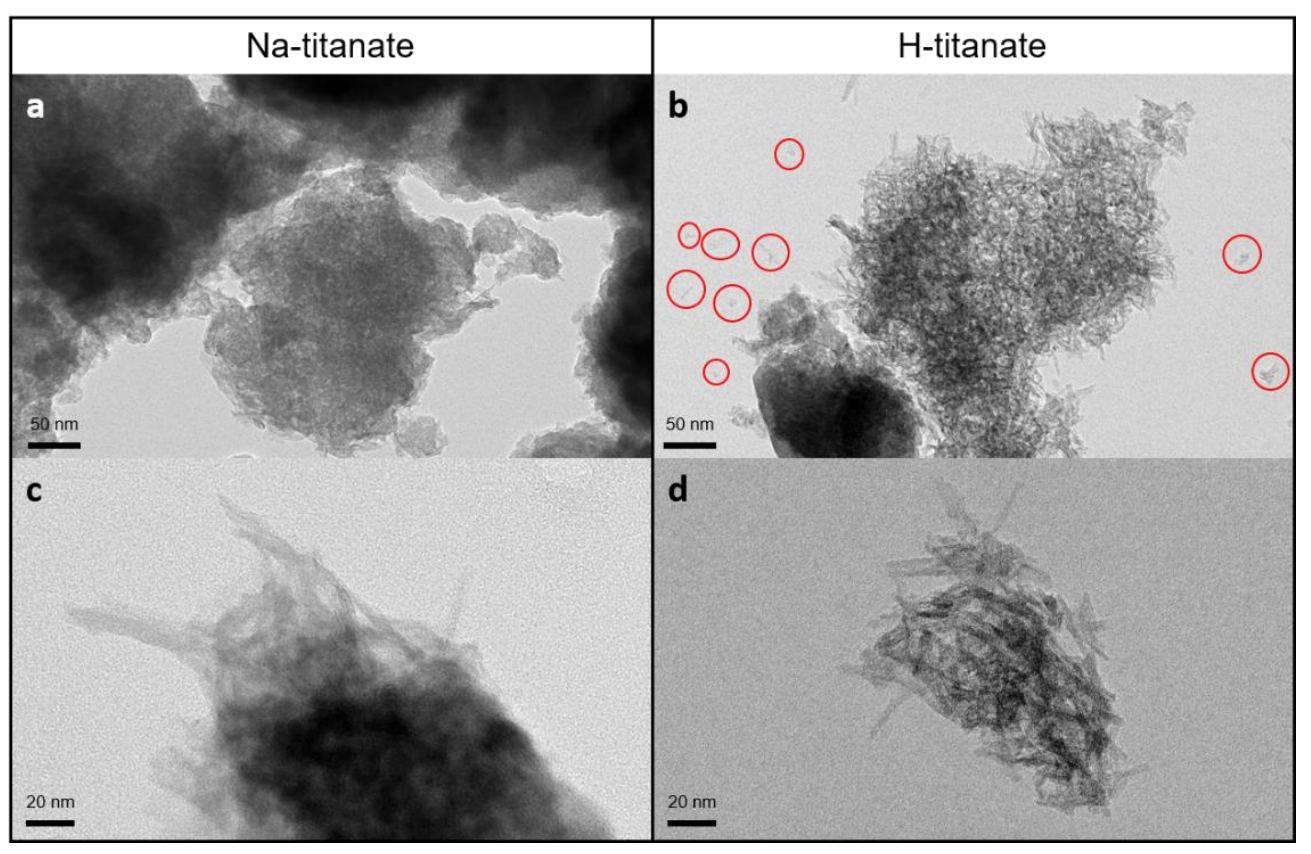

Fig. S6. TEM images of Na-titanate $(a, c)$ and $H$-titanate $(b, d)$. 


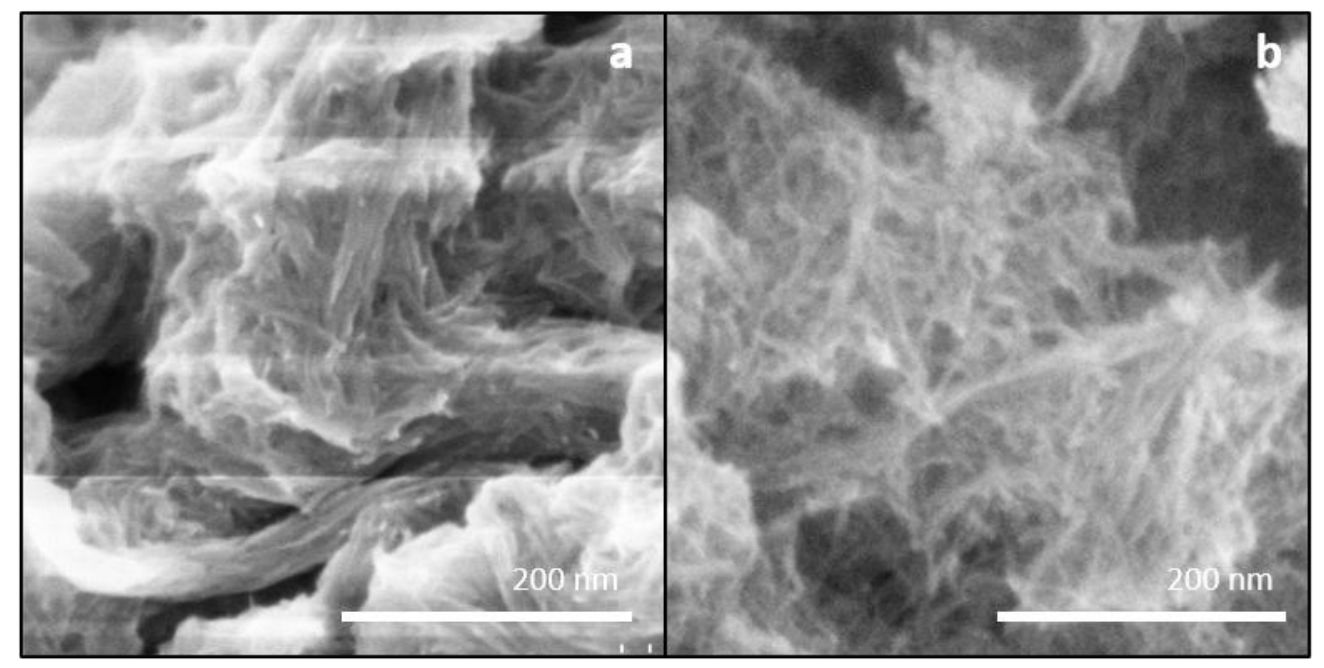

Fig. S7. SEM images of Na-titanate (a) and H-titanate (b)
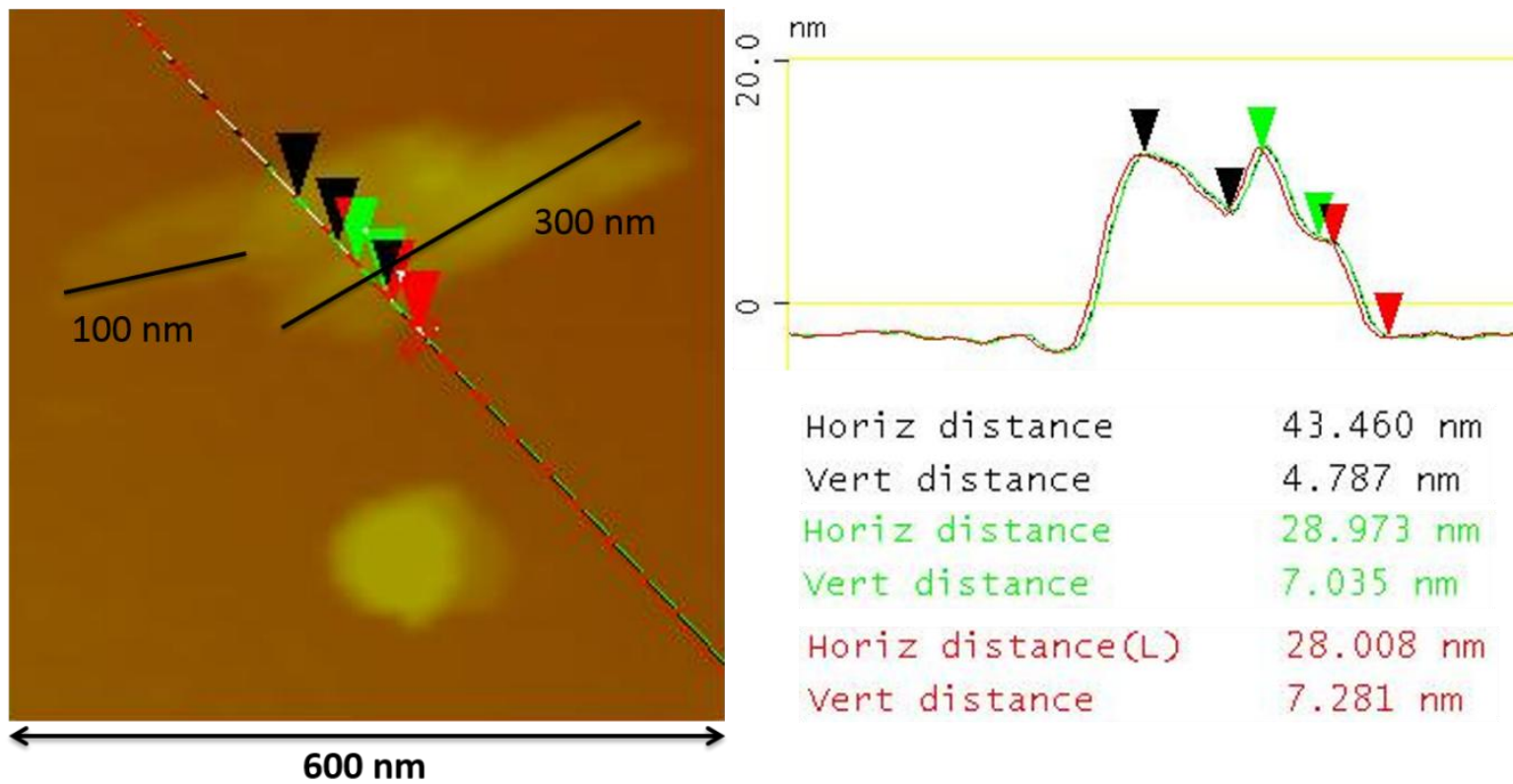

Fig. S8. Atomic force micrograph with a section of an aggregate of elongated particles of $\mathrm{H}$ titanate. Horizontal and vertical distances are between black, green, and red arrows. The longest sizes of two elongated particles are given in the picture. 


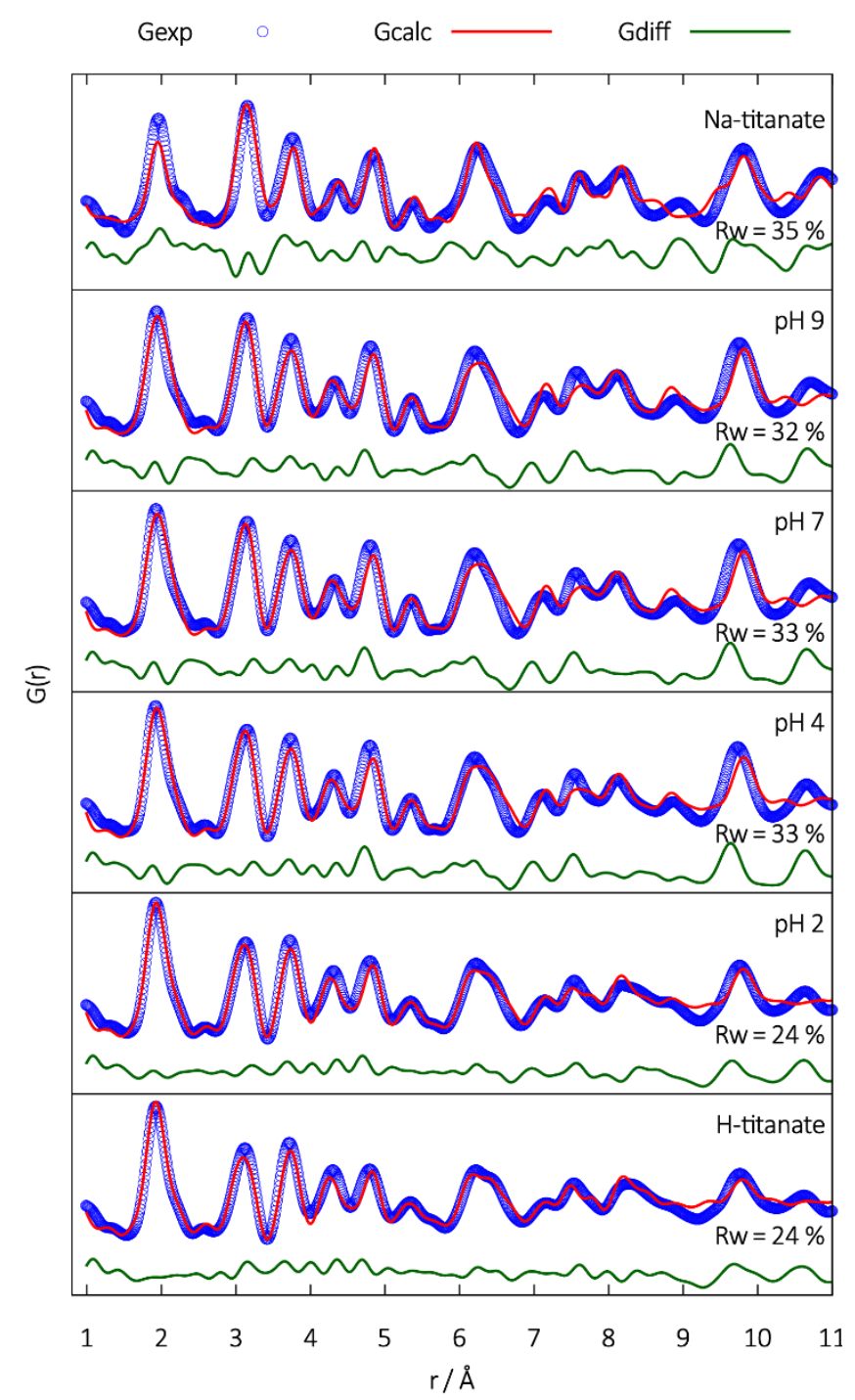

Fig. S9. Real-space refinements of the PDFs of the samples collected at different pH values. 

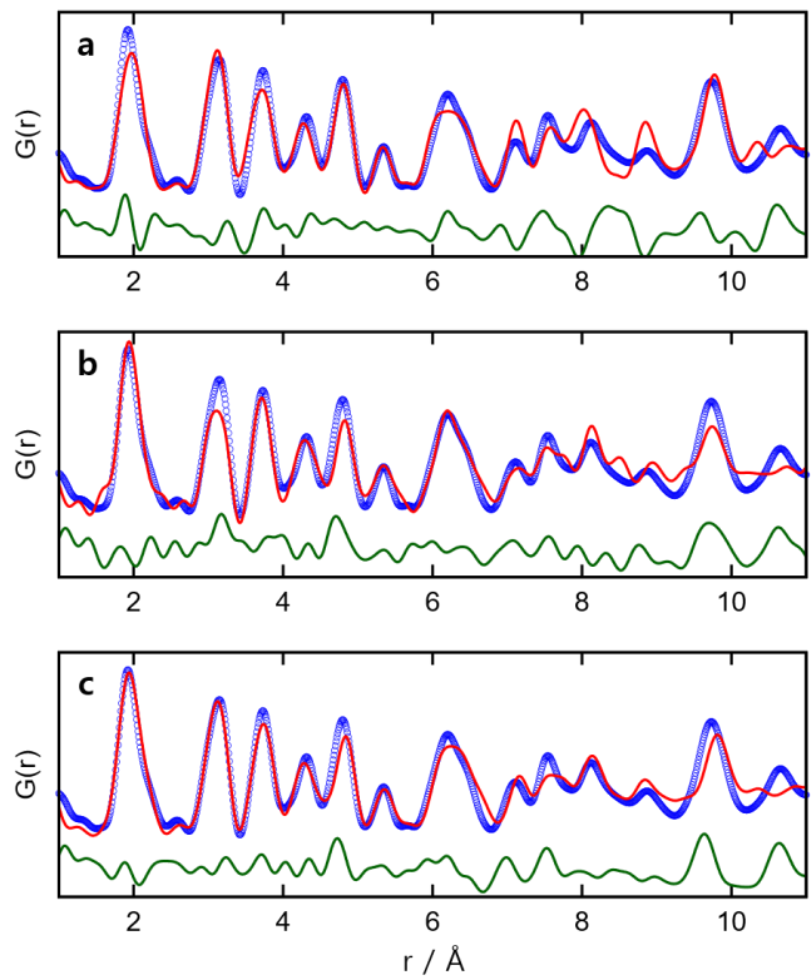

Fig. S10. Real-space refinements of the PDF of the sample collected at $\mathrm{pH} 4$ using lepidocrocite (a), trititanate (b), and both models (c). 


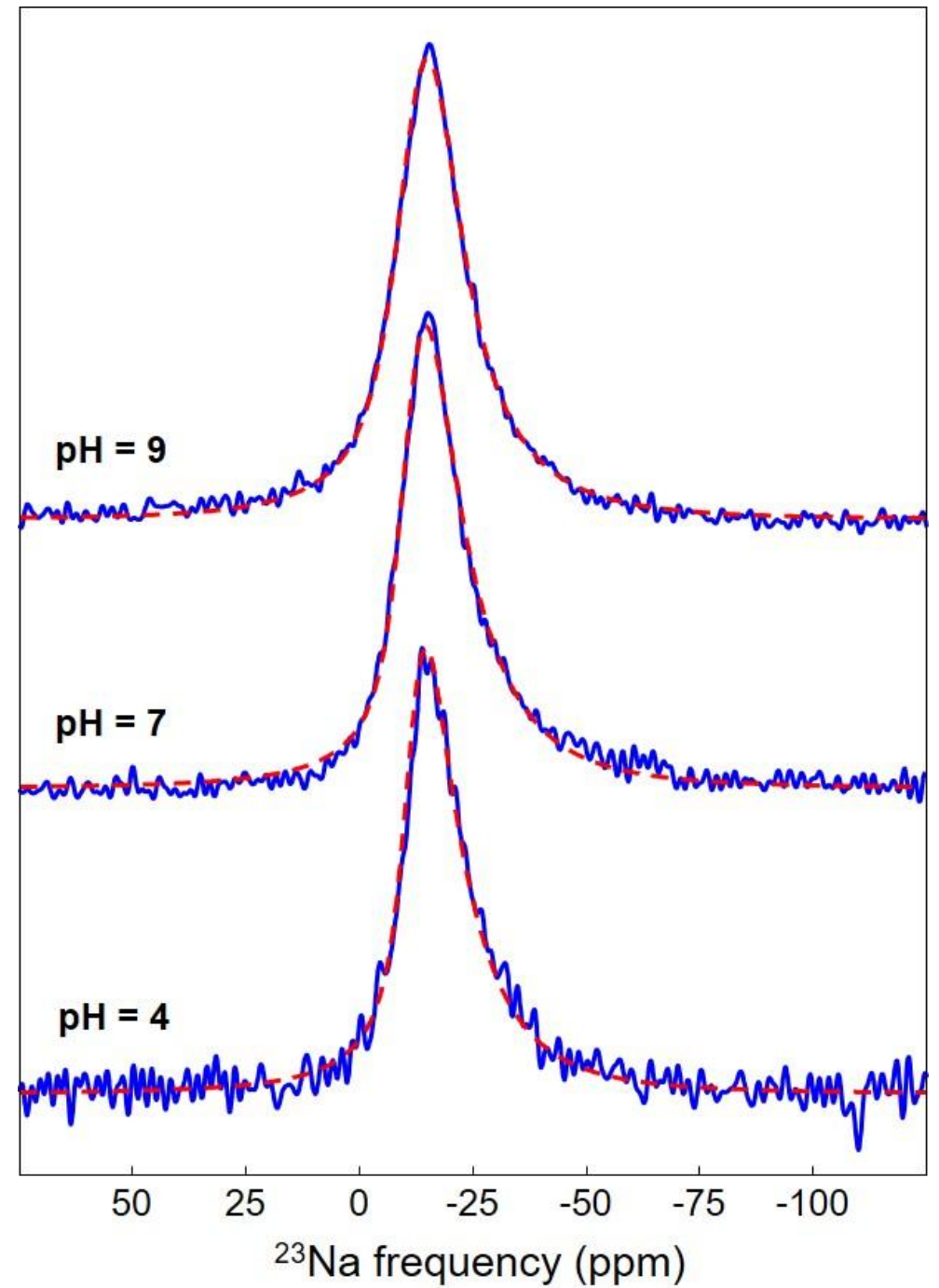

Fig. S11. Experimental (blue) and fitted using the Gaussian Isotropic Model ${ }^{1}$ (red dashed line) ${ }^{23} \mathrm{Na}$ MAS (44 kHz) NMR spectra of three samples collected at different $\mathrm{pH}$ values. This model involves a Gaussian distribution of chemical shifts and a distribution of quadrupolar interactions. The parameters used for these fits are reported in Table S1.

Table S1. Average isotropic chemical shift $\left(\left\langle\delta_{\text {iso }}\right\rangle / \mathrm{ppm}\right)$, full width at half maximum (FWHM) of the isotropic chemical shift Gaussian distribution $(\Delta \mathrm{CS} / \mathrm{ppm})$, average quadrupolar frequency $\left(\left\langle v_{\mathrm{Q}}\right\rangle / \mathrm{kHz}\right)$ and quadrupolar constant $\left(\left\langle\mathrm{C}_{\mathrm{Q}}\right\rangle / \mathrm{MHz}\right)$ used to fit the ${ }^{23} \mathrm{Na}$ MAS NMR spectra of three samples collected at different $\mathrm{pH}$ values (see Fig. S8).

\begin{tabular}{lllll}
\hline $\mathrm{pH}$ & $\left\langle\delta_{\text {iso }}\right\rangle$ & $\Delta \mathrm{CS}$ & $\left\langle v_{\mathrm{Q}}\right\rangle$ & $\left\langle\boldsymbol{C}_{\mathrm{Q}}\right\rangle$ \\
\hline 9 & -12.6 & 9.1 & 515 & 1.03 \\
7 & -11.3 & 7.0 & 668 & 1.34 \\
4 & -11.7 & 5.8 & 631 & 1.26 \\
\hline
\end{tabular}

\footnotetext{
${ }^{1}$ D. Massiot, F. Fayon, M. Capron, I. King, S. Le Calvé, B. Alonso, J.-O. Durand, B. Bujoli, Z. Gan and G. Hoatson, Modelling one- and two-dimensional solid-state NMR spectra: Modelling 1D and 2D solid-state NMR spectra, Magn. Reson. Chem., 2002, 40, 70-76.
} 


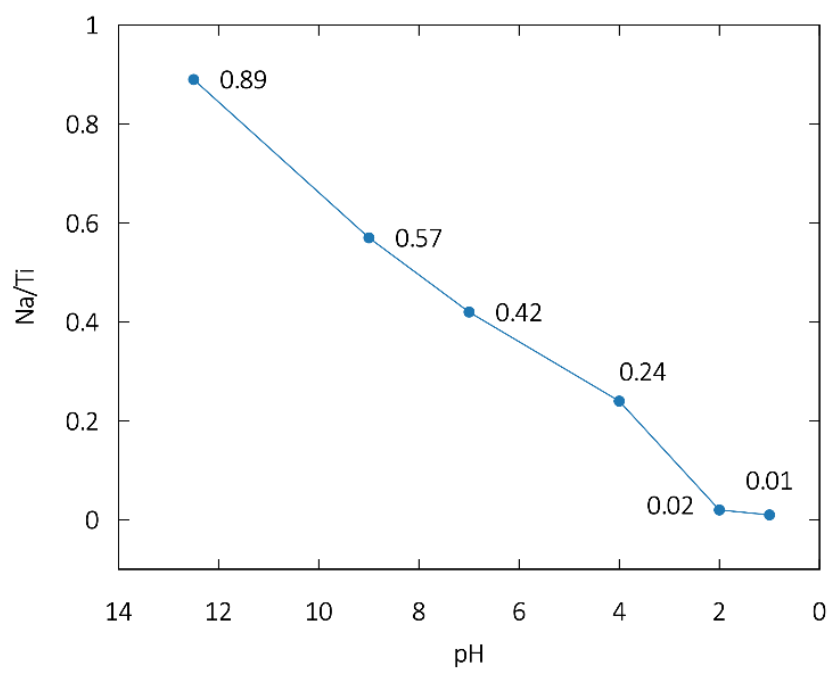

Fig. S12. Na/Ti ratio quantified using energy dispersive $\mathrm{X}$-ray spectroscopy for the samples collected at different $\mathrm{pH}$.

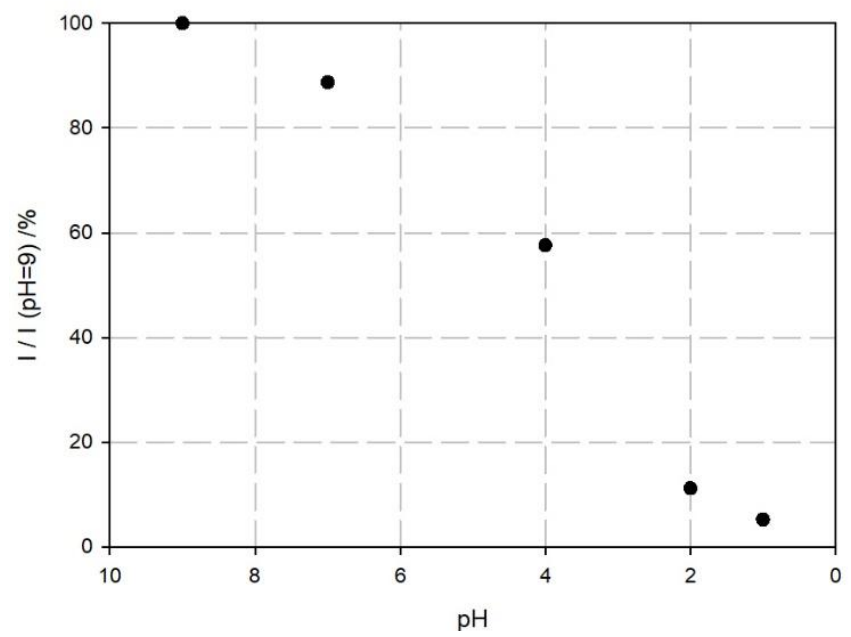

Fig. S13. Intensity / Intensity $(\mathrm{pH}=9)$ ratio of the ${ }^{23} \mathrm{Na}$ non-normalized NMR spectra for the samples collected at different $\mathrm{pH}$. Intensity estimated as the area under the curve of the fit of each non-normalized spectrum. The ${ }^{23} \mathrm{Na}$ non-normalized spectra correspond, for each sample, to the same number of scans and the same sample mass in the rotor. 


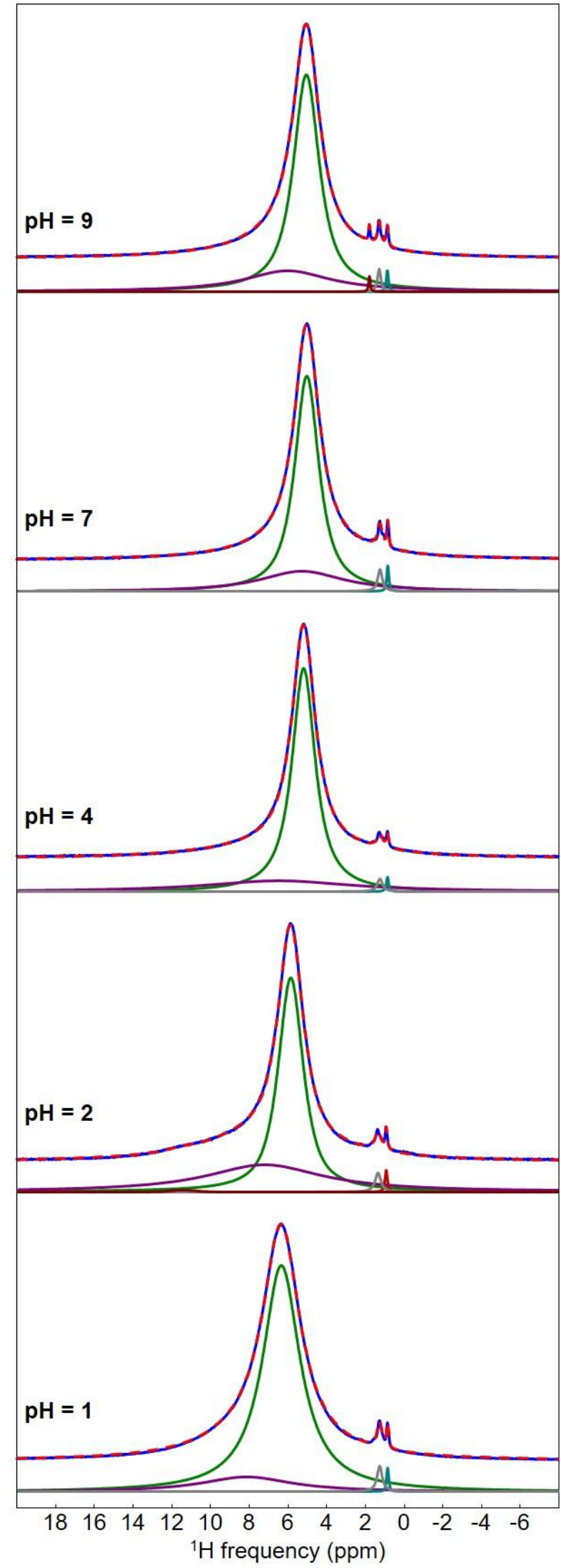

Fig. S14. Experimental (blue) and fitted (red dashed line) ${ }^{1} \mathrm{H}$ MAS (60 kHz) NMR spectra of the samples collected at different $\mathrm{pH}$. The individual resonances used for these fits are shown below (see Table S2). 
Table S2. Isotropic chemical shifts $\left(\delta_{\text {iso }} / \mathrm{ppm}\right)$, line widths $(\mathrm{LW} / \mathrm{ppm})$, relative intensities $(\mathrm{I} / \%)$, of the NMR resonances used for the fit of the ${ }^{1} \mathrm{H}$ MAS $(64 \mathrm{kHz})$ NMR spectra of the samples collected at different $\mathrm{pH}$ (see Fig. S11).

\begin{tabular}{|c|c|c|c|}
\hline $\mathrm{pH}$ & $\delta_{\text {iso }}$ & LW & I \\
\hline \multirow[t]{4}{*}{1} & 0.85 & 0.13 & 0.4 \\
\hline & 1.26 & 0.31 & 1.3 \\
\hline & 6.3 & 2.3 & 84.9 \\
\hline & 8.1 & 5.7 & 13.4 \\
\hline \multirow[t]{5}{*}{2} & 0.92 & 0.14 & 0.6 \\
\hline & 1.35 & 0.36 & 1.3 \\
\hline & 5.9 & 1.6 & 60.3 \\
\hline & 7.2 & 7.3 & 37.5 \\
\hline & 11.4 & 1.5 & 0.3 \\
\hline \multirow[t]{4}{*}{4} & 0.85 & 0.14 & 0.5 \\
\hline & 1.25 & 0.34 & 1.0 \\
\hline & 5.2 & 1.5 & 74.6 \\
\hline & 6.5 & 9.1 & 23.9 \\
\hline \multirow[t]{4}{*}{7} & 0.84 & 0.12 & 0.7 \\
\hline & 1.24 & 0.28 & 1.4 \\
\hline & 5.0 & 1.5 & 73.5 \\
\hline & 5.3 & 5.3 & 24.4 \\
\hline \multirow[t]{5}{*}{9} & 0.86 & 0.13 & 0.6 \\
\hline & 1.28 & 0.20 & 1.0 \\
\hline & 1.8 & 0.09 & 0.3 \\
\hline & 5.1 & 1.6 & 74.5 \\
\hline & 6.0 & 5.4 & 23.6 \\
\hline
\end{tabular}



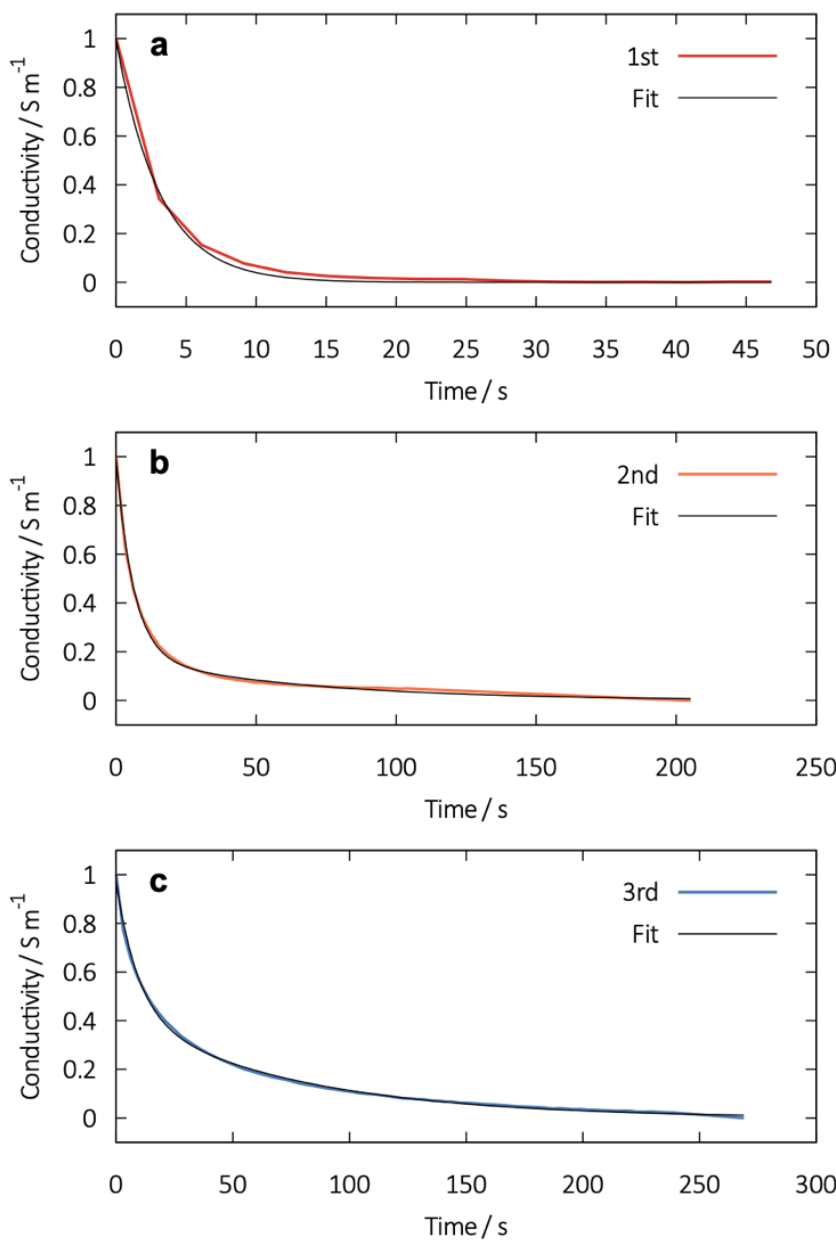

Fig. S15. Results of to fit the decay of the ionic conductivity during the $\mathrm{Na}^{+}-\mathrm{H}^{+}$ionic exchange. 